\title{
Use of a pair of blood culture bottles for sterility testing of corneal organ culture media
}

\author{
Philippe Gain, Gilles Thuret, Christophe Chiquet, Anne-Catherine Vautrin,
} Anne Carricajo, Sophie Acquart, Jean Maugery, Gérald Aubert

\begin{abstract}
Aims-To test the effectiveness and rapidity of a pair of blood culture bottles in the diagnosis of bacterial and fungal contamination of corneal organ culture media.

Methods-761 microbiological analyses of storage media (Inosol and Exosol, Opsia, Toulouse, France), sampled in all phases of the organ culture at $31^{\circ} \mathrm{C}$ of 410 consecutive corneas, were analysed. Each medium was inoculated in a pair of Bactec Plus Aerobic/F and Bactec Lytic/10 Anaerobic/F blood bottles and placed in a Bactec 9240 incubator for 14 days at $37^{\circ} \mathrm{C}$ and in a Sabouraud broth at $20^{\circ} \mathrm{C}$. Changes in colour or turbidity of storage media were evaluated daily at the corneal bank. Recipients were screened post-graft for infectious signs.

Results-Overall contamination rate was $2.4 \%(18 / 761)$. Contamination was detected in less than 1 day in $78 \%(14 / 18)$ and less than 2 days in $94 \%$ (17/18). Positivity of the microbiological controls of starting media preceded changes medium colour in 10 out of 14 cases. Bactec blood bottles allowed detection of bacteria as well as yeasts.

Conclusion-The use of a pair of Bactec blood culture bottles appears reliable for the rapid diagnosis of a wide range of microbiological contaminations of organ cultured corneas during banking.

(Br F Ophthalmol 2001;85:1158-1162)
\end{abstract}

Corneal storage in organ culture is the most common preservation technique in Europe. Compared with storage at $+4^{\circ} \mathrm{C}$, it allows better detection of pregraft microbiological contaminations, as well extended storage time.

Organ culture was originally introduced in order to extend cornea storage time to more than 10-14 days, a duration beyond which $+4^{\circ} \mathrm{C}$ techniques no longer ensure the viability of endothelial cells. Organ culture, which is currently most used in Europe, ${ }^{1}$ has the advantage of better preserving tissue viability, easing exchanges between cornea banks, and allowing more flexible scheduling of grafts. ${ }^{2-4}$ However, owing to the high temperature involved, organ culture presents a greater risk of microorganism development. So although it is well known that reducing storage time increases endothelial viability, corneas are not usually delivered by the banks until they have spent at least 10-12 days in organ culture, the period required to reveal any bacterial or fungal contamination using conventional bacteriological techniques and/or to observe any macroscopic changes in the storage medium.

Microbiological controls are typically performed using standard bacteriological media in aerobic and anaerobic atmospheres, and Sabouraud broth. Micro-organism development is monitored by the bacteriology department technician, who does daily visual inspections of the inoculated media. We therefore felt it desirable to implement the most advanced microbiological techniques to ensure maximum safety in the shortest time, in order to reduce the quarantine period without compromising the microbiological safety of the grafts.

We thus designed an original protocol for controlling cornea organ culture storage media using a pair of aerobic and anaerobic Bactec blood bottles (Becton Dickinson, Cockeysville, MD, USA). The bottles were placed in an automat with a system for automated reading of micro-organism growth.

The aim of this study was to test the effectiveness and rapidity of this original protocol in the diagnosis of bacterial and fungal contamination. We analysed the results of 761 microbiological samples of storage media taken in all phases of the organ culture of 410 corneas.

\section{Materials and methods}

CORNEA HARVESTING

The corneas were harvested within 24 hours of donor death, as follows: removal in aseptic surgical conditions by one of the four ophthalmologists of our hospital; the ocular surface was rinsed with sterile saline and then decontaminated with a $5 \%$ povidone-iodine solution for 3 minutes; the skin was then decontaminated with povidone-iodine and the ocular surface was rinsed with sterile saline. ${ }^{56}$ Corneas were excised with a $2 \mathrm{~mm}$ scleral rim and immediately placed in a first starting medium of $100 \mathrm{ml}$ of Inosol (Chauvin-Opsia, Toulouse, France). This was an enriched cell culture medium (modified Dulbecco's medium) containing penicillin $\mathrm{G}(100 \mathrm{IU} / \mathrm{ml})$, streptomycin 
$(100 \mu \mathrm{g} / \mathrm{ml})$, and amphotericin B $(0.25 \mu \mathrm{g} / \mathrm{ml})$ and a colorimetric $\mathrm{pH}$ indicator (phenol red).

ORGAN CULTURE AT $31^{\circ} \mathrm{C}$

The corneas were immediately stored in organ culture at $31^{\circ} \mathrm{C}$ according to the conventional technique. ${ }^{7}$ All cornea handling and media replacement and sampling were done under a laminar flow hood. Two to 5 days after cornea reception, the first endothelial quality control was done. This included cell counting, cell morphology assessment, and vital staining using trypan blue. The cornea was transferred to another bottle containing $100 \mathrm{ml}$ of Inosol, called the storage medium. The cornea was transferred to fresh medium if storage exceeded 14 days (for 15 corneas in our study). Finally, 2 days before delivery, the cornea underwent a second endothelial quality control (same protocol as above) and was placed in a so called deswelling medium of $50 \mathrm{ml}$ of Exosol (Chauvin-Opsia). The Exosol medium was identical to the Inosol medium, plus $5 \%$ of dextran.

Over a 37 month period (September 1996 to October 1999), 410 corneas were harvested. Seventy six corneas were immediately discarded for medical contraindication or serological reasons (lack or haemolysis of donor blood, positivity). Three hundred and thirty four corneas were organ cultured. After the first endothelial quality control, 206 corneas were returned to the storage medium for a mean duration of 13.2 days (SD 4, range 6-28 days). By the end of storage, 206 corneas had been placed in deswelling medium before grafting.

MICROBIOLOGICAL ANALYSIS

For each medium, we did a daily visual inspection of colour and turbidity. Any medium turbidity or colour change caused the cornea to be discarded, and a sample was taken for microbiological analysis.

At each medium change, $25 \mathrm{ml}$ of medium were systematically sampled under a laminar flow hood at the eye bank: between 2 and 5 days after cornea reception (starting media); at the possible replacement on day 14 of storage; and 2 days before delivery (storage medium). Finally, on graft day, the deswelling medium samples were collected in the operating room during the operation. Each sample was immediately taken in a sterile bottle to the bacteriology department for analysis.

Each sample was inoculated in the bacteriology laboratory under a laminar flow hood according to a standard procedure. Ten $\mathrm{ml}$ were injected into an Bactec Plus Aerobic/F bottle containing $25 \mathrm{ml}$ of enriched soybeancasein digest broth, $16 \%$ (wt/vol) non-ionic adsorbent resin and $1 \%(\mathrm{wt} / \mathrm{vol})$ cationic exchange resins. Ten $\mathrm{ml}$ were injected in a Bactec Lytic/10 Anaerobic/F bottle containing $40 \mathrm{ml}$ of soybean-casein digest broth, $0.26 \%$ (wt/vol) of saponin. The bottles were placed in a Bactec 9240 incubator for 14 days and rocked continuously at $37^{\circ} \mathrm{C}$. The incubator detected any rise in the carbon dioxide produced by bacterial growth. A sensor placed at the bottom of each bottle reacted with the carbon dioxide and produced fluorescence proportional to the carbon dioxide level. The incubator measured this fluorescence by a non-invasive technique every 10 minutes, and micro-organism development was detected according to a fluorescence threshold set by the manufacturer.

Five $\mu \mathrm{l}$ of medium were inoculated in $10 \mathrm{ml}$ of Sabouraud broth and placed in an incubator at $20^{\circ} \mathrm{C}$.

If positivity was detected in the blood bottle or Sabouraud broth, the cornea was discarded, micro-organisms were identified, and sensitivity to antibiotics or antifungi was tested.

\section{FOLLOW UP OF GRAFTED PATIENTS}

The clinical outcome of the 206 grafted patients was controlled daily at a single institution by slit lamp examination on the 5 postoperative days, then on day 15 and at $1,3,6,9$, and 12 months after the graft. Any signs of ocular infection were searched during the biomicroscopic examination done at each visit.

\section{Results}

PREVALENCE AND CHRONOLOGY OF MICROBIOLOGICAL CONTAMINATIONS

In all, 761 samples were analysed-334 starting media, 221 storage media, and 206 deswelling media. Eighteen microbiological controls were positive (18/761), an overall contamination rate of $2.4 \%$. This rate was $4.2 \%(14 / 334)$ for starting media, $0 \%(0 / 221)$ for storage media, and $1.9 \%(4 / 206)$ for deswelling media. Excluding the deswelling media control, the contamination rate during storage was $2.5 \%(14 / 555)$.

Fourteen out of 18 micro-organisms were isolated from the starting media. Table 1 gives the microbiological results of the contaminated starting media, Inosol colour changes observed at the corneal bank at the time of control, time between inoculation and positivity, the overall time between corneal harvesting and positivity of the Bactec bottles, and the sensitivity of micro-organisms to the anti-infectious agents of the medium. Time between inoculation and positivity of the pair of Bactec bottles inoculated with the starting medium was either 1 day $(12 / 14)$ or 2 days (2/14). Positivity of the microbiological controls preceded changes in storage medium colour in 10 out of 14 cases.

Four of the 18 micro-organisms were isolated from the deswelling media (Table 2). The time to positivity of the Bactec bottles inoculated with the deswelling media was 1 day $(2 / 4), 2$ days $(1 / 4)$, or 6 days $(1 / 4)$. No infection was observed in the four recipients.

The isolated bacteria were all multiresistant to the antibiotics, particularly the antibiotics in the storage media, except for the two Escherichia coli (Table 1) and one Staphylococcus aureus (Table 2), which were sensitive to all the aminosides. In addition, all yeasts (Tables 1 and 2) were sensitive to the amphotericin B present in very low concentration $(0.25 \mu \mathrm{g} / \mathrm{ml})$ in the media. It should be noted that the pair of Bactec bottles allowed detection of all the yeasts (five Candida spp, 1 Rhodotorula spp) as 
Table 1 Microbiological contaminations of starting media $(n=14 / 334)$

\begin{tabular}{|c|c|c|c|c|c|c|c|c|}
\hline \multirow[b]{2}{*}{ Isolated micro-organism } & \multirow[b]{2}{*}{$\begin{array}{l}\text { Changes in medium } \\
\text { colour at time of } \\
\text { control }\end{array}$} & \multicolumn{3}{|c|}{$\begin{array}{l}\text { Time between inoculation and positive } \\
\text { control (days) }\end{array}$} & \multirow{2}{*}{$\begin{array}{l}\text { Time between } \\
\text { corneal harvesting } \\
\text { and positive control } \\
\text { (days) }\end{array}$} & \multicolumn{3}{|c|}{$\begin{array}{l}\text { Sensitivity of micro-organisms for the } \\
\text { anti-infectious agents present in medium }\end{array}$} \\
\hline & & $\begin{array}{l}\text { Bactec } \\
\text { aerobic } \\
\text { bottle }\end{array}$ & $\begin{array}{l}\text { Bactec } \\
\text { anaerobic } \\
\text { bottle }\end{array}$ & $\begin{array}{l}\text { Sabouraud } \\
\text { broth }\end{array}$ & & Penicillin $G$ & Streptomycin & Amphotericin $B$ \\
\hline Staphylococcus aureus & No & 1 & 1 & - & 4 & $\mathrm{R}$ & $\mathrm{R}$ & $\mathrm{R}$ \\
\hline Staphylococcus aureus & Yes & 1 & 1 & - & 4 & $\mathrm{R}$ & $\mathrm{R}$ & $\mathrm{R}$ \\
\hline Staphylococcus aureus & Yes & 1 & 1 & - & 4 & $\mathrm{R}$ & $\mathrm{R}$ & $\mathrm{R}$ \\
\hline Coagulase negative staphylococcus & No & 1 & 1 & - & 6 & $\mathrm{R}$ & $\mathrm{R}$ & $\mathrm{R}$ \\
\hline Coagulase negative staphylococcus & No & 1 & 1 & - & 6 & $\mathrm{R}$ & $\mathrm{R}$ & $\mathrm{R}$ \\
\hline Pseudomonas vesicularis & No & 1 & - & - & 5 & $\mathrm{R}$ & $\mathrm{R}$ & $\mathrm{R}$ \\
\hline Pseudomonas vesicularis & No & 1 & - & - & 5 & $\mathrm{R}$ & $\mathrm{R}$ & $\mathrm{R}$ \\
\hline Escherichia coli & No & 1 & 1 & - & 4 & $\mathrm{R}$ & $\mathrm{S}$ & $\mathrm{R}$ \\
\hline Escherichia coli & No & 1 & 1 & - & 4 & $\mathrm{R}$ & $\mathrm{S}$ & $\mathrm{R}$ \\
\hline Candida albicans & No & 1 & 1 & 1 & 5 & $\mathrm{R}$ & $\mathrm{R}$ & $\mathrm{S}$ \\
\hline Candida albicans & Yes & - & 1 & 1 & 4 & $\mathrm{R}$ & $\mathrm{R}$ & $\mathrm{S}$ \\
\hline Candida albicans & Yes & - & 1 & 4 & 4 & $\mathrm{R}$ & $\mathrm{R}$ & S \\
\hline Candida glabrata & No & 2 & 2 & 2 & 6 & $\mathrm{R}$ & $\mathrm{R}$ & $\mathrm{S}$ \\
\hline Candida glabrata & No & 2 & 2 & 2 & 6 & $\mathrm{R}$ & $\mathrm{R}$ & $\mathrm{S}$ \\
\hline
\end{tabular}

- = No micro-organism growth, $\mathrm{R}=$ resistant, $\mathrm{S}=$ sensitive.

Table 2 Microbiological contaminations of deswelling media $(n=4 / 206)$

\begin{tabular}{|c|c|c|c|c|c|c|c|}
\hline \multirow[b]{2}{*}{ Isolated micro-organism } & \multicolumn{3}{|c|}{ Time between inoculation and positive control (days) } & \multicolumn{3}{|c|}{$\begin{array}{l}\text { Sensitivity of micro-organisms to the anti-infectious agents } \\
\text { present in medium }\end{array}$} & \multirow{2}{*}{$\begin{array}{l}\text { Postoperative } \\
\text { infectious } \\
\text { complications }\end{array}$} \\
\hline & $\begin{array}{l}\text { Bactec aerobic } \\
\text { bottle }\end{array}$ & $\begin{array}{l}\text { Bactec anaerobic } \\
\text { bottle }\end{array}$ & $\begin{array}{l}\text { Sabouraud } \\
\text { broth }\end{array}$ & Penicillin $G$ & Streptomycin & Amphotericin B & \\
\hline Staphylococcus aureus & - & 2 & - & $\mathrm{R}$ & $\mathrm{S}$ & $\mathrm{R}$ & No \\
\hline Coagulase negative staphylococcus & 1 & 1 & - & $\mathrm{R}$ & $\mathrm{R}$ & $\mathrm{R}$ & No \\
\hline Coagulase negative staphylococcus & 1 & 1 & - & $\mathrm{R}$ & $\mathrm{R}$ & $\mathrm{R}$ & No \\
\hline Rhodotorula spp & 6 & - & - & $\mathrm{R}$ & $\mathrm{R}$ & $\mathrm{S}$ & No \\
\hline
\end{tabular}

- = No micro-organism growth, $\mathrm{R}=$ resistant, $\mathrm{S}=$ sensitive.

quickly as Sabouraud's specific broth. The microbiological controls turned positive in less than 1 day in $78 \%$ of cases (14/18) and in less than 2 days in $94 \%(17 / 18)$ of cases.

CLINICAL CORRELATIONS

In the 206 grafted patients we noted one case of hypopyon, which occurred 24 hours after grafting. No micro-organism could be isolated, the deswelling medium was sterile and the patient was cured after 10 days of antibiotherapy. The four patients whose deswelling medium control returned positive after grafting did not present infectious complications.

\section{Discussion}

Sterility controls of corneal organ culture media cornea storage in organ culture at $31^{\circ} \mathrm{C}$ cut the risk of infectious contamination of the recipient by eliminating the clinical use of contaminated or potentially contaminating corneas. ${ }^{78}$ Micro-organisms find optimal growth conditions in organ culture, hence the need to add anti-infectious agents to the storage media. However, it is still necessary to carry out sterility controls during the cornea storage process. These controls are usually done by inoculation in trypticase-soybean type media to isolate aerobic and anaerobic bacteria, and in thioglycollate type media for the isolation of strict anaerobias and micro-aerophilias. ${ }^{9} 10$

The type of Bactec blood bottle incubated in the Bactec 9240 automat were first used for the bacteriological analysis of blood samples because of their greater sensitivity and capacity to shorten detection time of bacterial growth. ${ }^{11}$ Since then, various authors have shown that blood bottles are superior to standard methods for the bacteriological analysis of non-blood samples such as ascitic fluid, ${ }^{12}$ kidney dialysis fluids, ${ }^{13}{ }^{14}$ articular fluids, ${ }^{15}{ }^{16}$ and cerebrospinal fluids. ${ }^{17}$ All these media have in common a low bacteria inoculum. We therefore felt justified in using this technique for sterility controls of corneal organ culture media.

This method offers many advantages over the standard microbiological technique. Sample inoculation by direct injection into bottles sealed under a laminar flow hood minimises the risk of contamination by handling. The large quantity of broth in each Bactec bottle allows better detection of low bacterial inoculum, which is theoretically the case with cornea storage media. The presence of antibiotic neutralising resins in Bactec Plus Aerobic/F bottles $^{18}$ and of saponin in Bactec Lytic/10 Anaerobic/F bottles $^{19}$ promotes microorganism growth. The constant rocking of the bottles by the automat accelerates the growth of most bacteria. Finally, the computerised and non-invasive monitoring of bacterial growth, with measuring every 10 minutes, accelerates positivity detection and limits exogenous contamination. ${ }^{11}$ As a result, the time to positivity of the 18 Bactec bottles was always less than 2 days, except for one bottle which was positive in 6 days for the yeast Rhodotorula spp. This short time allows grafting with high microbiological safety 6 days after corneal harvesting. It should also be noted that only four out of 18 positive controls presented a change in colour at the time of the control. As a result, contamination was detected before the medium colour change 14 times out of 18 . This allowed contaminated corneas to be discarded early in the storage process.

Despite the extreme rareness of post-graft fungal endophthalmitis, detection of fungal contamination remains a major concern for ophthalmologists because of its potentially 
severe effects. ${ }^{20-22}$ In our study, the use of Bactec bottles allowed the detection of fungi (6/6), especially of the Candida type. However, the use of conventional Sabouraud broth remains essential to detect filamentous fungi. Although several authors have demonstrated that Bactec Aerobic Plus/F and Bactec Lytic/10 Anaerobic/ $\mathrm{F}$ bottles are highly effective in detecting yeasts and filamentous organisms, ${ }^{23}{ }^{24}$ the use in our study of a conventional Sabouraud broth allowed to check the effective detection by the Bactec bottles of the presence of fungi in the organ culture media. ${ }^{25}$

A major study of fungal contamination during organ culture determined a mean time to positivity of 11 days $^{26}$ and a median of 9 days, with a linear relation between storage time and prevalence of fungal contamination. But the author used only a conventional Sabouraud broth. This suggests that an extended storage time would enable a weak inoculum of yeasts, initially undetectable, to develop and reach the threshold of detection by the traditional microbiological methods used at that time. We believe that the use of blood bottles, which optimises both fungal growth and the speed of detection, can allow earlier elimination of contaminated corneas with no detriment to the recipient. It is with this aim that in future we will replace conventional Sabouraud broth with a Bactec (Mycosis IC/F) fungal bottle, which has proved its effectiveness in detecting fungal septicaemia more rapidly. ${ }^{23}$

Unlike some authors ${ }^{7}{ }^{10}$ who do not change the cornea starting medium but monitor its colour daily (for turbidity or a change in colour), we systematically changed the starting medium under laminar flow hood when doing the first microbiological and endothelial control during the first 5 days. This early change of medium allows both the elimination of any micro-organisms present in low quantities in the medium but also the renewal of the anti-infectious agents. Our low starting media contamination rate $(4.2 \%)$ compared with that of Erbezci et $a l^{10}(15.7 \%)$ or that of Borderie et $a l^{8}(11 \%)$ could be partly explained by this storage protocol. All 206 corneas which benefited from this initial medium renewal remained sterile throughout the storage process.

In our study, mean cornea storage time was 13.4 days (SD 4). Most authors agree that corneas require a minimum period of storage in culture medium, called quarantine, in order to maximise the elimination of contaminated corneas: Erbezci et $a l^{10}$ recommend at least 8 days and Laroche ${ }^{27}$ at least 14 days. Conversely, it is established that endothelial cell density, which is one of the main factors in the long term survival of the graft, drops as storage time rises. ${ }^{28}$ Consequently, cutting storage time without compromising microbiological safety seems an important objective for corneal bankers.

Our work (Table 1) shows that a minimum period of storage in organ culture of 6 days would assure maximum microbiological safety as all contamination cases were detected before day 6 after cornea harvesting ( 4 days for $7 / 14$, 5 days for 3/14, and 6 days for $4 / 14$ corneas).
Reisner et al recently studied 23686 blood cultures and 693 articular fluids inoculated in a pair of Bactec blood bottles and placed in a Bactec 9240 incubator. The 2803 pathogenic agents (including 88 Candida spp) and the 1609 micro-organisms considered to be contaminants were all detected within 8 days. ${ }^{29}$ The routine use of this microbiological control protocol could therefore shorten the quarantine period of corneas in organ culture without compromising the microbiological safety of the grafted patients' corneas. In our study, only one patient presented a limited postoperative infection (hypopyon). It should be noted that all the microbiological controls in this case were negative and that the hypothesis of contamination during surgery cannot be ruled out. Further, no postoperative infection was found in the four patients with a cornea whose deswelling medium proved positive. These contamination cases were probably linked to sampling, which was done in non-standard conditions in the operating room and not under a laminar flow hood. Direct injection of the deswelling medium into the blood bottle by the surgeon should reduce the risk of false positives.

The use of a pair of aerobic and anaerobic blood culture bottle is a simple, effective, and rapid method for sterility control of organ cultured corneas. The validation of this protocol will require a randomised study to compare it with the conventional microbiological method.

Presented in part at the annual meeting of the European association for Vision and Eye Research, Spain, October 2000. We thank Dr A Tullo for his suggestions on the preparation of this manuscript.

The authors do not have any proprietary interest in the materials used in this study.

1 Pels L. Organ culture: the method of choice for preservation of human donor corneas. Br f Ophthalmol 1997;81:523-5. 2 Doughman DJ, Harris JE, Schmitt MK. Penetrating keratoplasty using $37^{\circ} \mathrm{C}$ organ cultured cornea. Trans Am Acad Ophthalmol Otolaryngol 1976;81:778-93.

3 Doughman DJ. Prolonged donor cornea preservation in Doughman DJ. Prolonged donor cornea preservation in
organ culture: long-term clinical evaluation. Trans $\mathrm{Am}$ organ culture: long-term clinical
Ophthalmol Soc 1980;78:567-628.

4 Pels E, Schuchard Y. Organ-culture preservation of human corneas. Doc Ophthalmol 1983;56:147-53.

5 Pels E, Vrensen GF. Microbial decontamination of human donor eyes with povidone-iodine: penetration, toxicity, and effectiveness. Br F Ophthalmol 1999;83:1019-26.

6 Mindrup EA, Dubbel PA, Doughman DJ. Betadine decontamination of donor globes. Cornea 1993;12:324-9.

7 Delbosc B, Borderie V. [Methods of preservation of the human corneas.] F Fr Ophtalmol 1997;20:221-40.

8 Borderie VM, Laroche L. Microbiologic study of organcultured donor corneas. Transplantation 1998;66:120-3.

9 Hagenah M, Bohnke M, Engelmann K, et al. Incidence of bacterial and fungal contamination of donor corneas preserved by organ culture. Cornea 1995;14:423-6.

10 Erbezci M, Monnot PH, Michel-Briand Y, et al. [Organ culture preservation of the human cornea at +31 degrees $\mathrm{C}$ ture preservation of the human cornea at +31 degrees
and risk of infection.] $f \mathrm{Fr}$ Ophtalmol 1995;18:106-13.

11 Nolte FS, Williams JM, Jerris RC, et al. Multicenter clinical evaluation of a continuous monitoring blood culture
system using fluorescent-sensor technology (BACTEC system using fluorescent-sensor tech

12 Runyon BA, Canawati HN, Akriviadis EA. Optimization of ascitic fluid culture technique. Gastroenterology 1988;95: $1351-5$

13 Saubolle MA, Sewell DL, Holland MD, et al. Comparison of two commercial broth-culture systems for microbial detection in dialysates of patients on continuous ambulatory peritoneal dialysis. Diagn Microbiol Infect Dis 1989;12: 457-61.

14 Rayner BL, Williams DS, Oliver S. Inoculation of peritoneal dialysate fluid into blood culture bottles improves culture rates. S Afr Med F 1993;83:42-3.

15 Von Essen R. Culture of joint specimens in bacterial arthritis. Impact of blood culture bottle utilization. Scand $\mathcal{F}$ Rheumatol 1997;26:293-300.

16 Yagupsky P, Dagan R, Howard CW, et al. High prevalence of Kingella kingae in joint fluid from children with septic
arthritis revealed by the BACTEC blood culture system. $\mathcal{F}$ Clin Microbiol 1992;30:1278-81. 
17 Fuller DD, Davis TE. Comparison of BACTEC plus Aerobic/F, Anaerobic/F, Peds Plus/F, and Lytic/F media with and without fastidious organism supplement conventional methods for culture of ster
Diagn Microbiol Infect Dis 1997;29:219-25.

18 Spaargaren J, van Boven CP, Voorn GP. Effectiveness of resins in neutralizing antibiotic activities in bactec plus Aerobic/ $\mathrm{F}$ culture medium. F Clin Microbiol 1998;36:3731-3.

19 Elliott TS, Stevens CM, Macrae F, et al. Improved recovery of antibiotic-stressed microorganisms on inclusion of saponin in aerobic blood culture media. Eur 7 Clin Microbiol Infect Dis 1998;17:566-9.

20 Antonios SR, Cameron JA, Badr IA, et al. Contamination of donor cornea: postpenetrating keratoplasty endophthalmitis. Cornea $1991 ; 10 \cdot 217-20$.

21 Kloess PM, Stulting RD, Waring GO, et al. Bacterial and fungal endophthalmitis after penetrating keratoplasty. [Published erratum appears in Am 7 Ophthalmol 1993;115: 548.] Am 7 Ophthalmol 1993;115:309-16.

22 Kunimoto DY, Das T, Sharma S, et al. Microbiologic spectrum and susceptibility of isolates: part I. Postoperative Ophthalmol 1999;128:240-2.
23 Fricker-Hidalgo H, Chazot F, Lebeau B, et al. Use of simulated blood cultures to compare a specific fungal medium with a standard microorganism medium for yeast detection. Eur f Clin Microbiol Infect Dis 1998;17:113-6.

24 Siemann M, Rabenhorst G. Detection of fungemia from blood cultures using the BACTEC 9240 instrument. Zentralbl Bakteriol 1998;287:53-5.

25 Jendral G, Wilhelm F, Bernhardt H, et al. [Difficulties of fungus detection in corneal culture medium.] Ophthalmologe 1999;96:465-7.

26 Nelson JD, Mindrup EA, Chung CK, et al. Fungal contamination in organ culture. Arch Ophthalmol 1983;101:280-3.

27 Laroche L, Borderie V, Lopez M, et al. [Microbiological safety and endothelial quality control during preservation of corneal grafts at +31 degree C.] $\mathcal{F}$ Fr Ophtalmol 1994;17: 314-20

28 Salla S, Redbrake C, Becker J, et al. Remarks on the vitality of the human cornea after organ culture. Cornea 1995;14: 502-8.

29 Reisner BS, Woods GL. Times to detection of bacteria and yeasts in Bactec 9240 blood culture bottles. F Clin Microbiol yeasts in Bactec 924 